\title{
Women and valproate: what should neurologists do?
}

\author{
John J Craig
}

\section{Correspondence to}

Dr John J Craig, Department of Neurology, Belfast Health and Social Care Trust, Belfast, BT12 6BA, UK; john.craig@ belfasttrust.hscni.net

Accepted 11 March 2018 Published Online First

23 April 2018

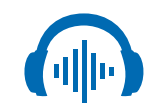

Listen to Podcast www.goo.gl/sNwjuh

\section{Sinked}

- http://dx.doi.org/10.1136/ practneurol-2018-001931 - http://dx.doi.org/10.1136/ practneurol-2018-001955

\section{Check for updates}

To cite: Craig JJ. Pract Neurol 2018;18:219-221.
Valproate first received its UK licence for treating epilepsy in 1973; reports of congenital malformations appeared within 10 years $^{1}$ and fetal valproate syndrome soon after. $^{2}$ More recently, pregnancy registries have provided information on the risks for major congenital malformations in pregnancies exposed to antiepileptic drugs, consistently showing greater risks to infants exposed to valproate: approximately $10 \%$ for monotherapy and dose-related. ${ }^{3-5}$ This is significantly higher than the background rate-pregnancies in women with epilepsy not taking antiepileptic drugs-and the rate with other antiepileptic drugs, including lamotrigine, levetiracetam and carbamazepine (table 1). ${ }^{3-5}$ Studies have defined the types of major congenital malformation associated with valproate, predominantly neural tube defects, clefting abnormalities, cardiovascular defects, genitourinary defects in male and musculoskeletal defects. However, it is the risk of neurodevelopmental disability, including cognitive impairment, autistic spectrum disorder and autism, that has resulted in recommendations to avoid valproate in women of childbearing years and in pregnancy, in particular. ${ }^{6}$ With some studies reporting risks of $30 \%-40 \%$ for certain aspects of neurodevelopment, such caution and plans to mitigate the risks seem justified. However, much is still to be learnt: the true overall risk for neurodevelopmental disability is unknown for valproate, a situation mirrored for all antiepileptic drugs.

Based on current knowledge and recent recommendations, what should neurologists do to support girls and women with epilepsy to make safe choices regarding their use of valproate? While many groups have been targeted to limit valproate exposure, clinicians should not give information on the risks of valproate in isolation, but rather as part of a comprehensive epilepsy assessment.
This has clear implications for neurologists and others providing specialist epilepsy services. In people with newly diagnosed epilepsy, determining the need for antiepileptic drug treatment and the most appropriate drug and its duration, and in those still prescribed valproate their requirement for ongoing medication, the suitability of alternatives, and the risks of its withdrawal with loss of seizure control (including the risks of sudden unexplained death in epilepsy and the psychosocial consequences) cannot be devolved to clinicians who are not fully skilled in managing all aspects of epilepsy care. At the most basic level, not all antiepileptic drugs are suitable for all seizures, and valproate withdrawal or switching to an alternative medication certainly risks the patient losing seizure control. This is also the case during pregnancy, where generalised tonic-clonic seizures were twice as common in those where valproate was withdrawn $(33 \% ; n=93)$, or replaced $(29 \% ; n=38)$ in pregnancy, compared with those who stayed on it $(16 \% ; n=1588){ }^{7}$

For those women who do require valproate and where alternatives have been considered or tried, are there options to reduce risk? Changing to the prolonged release preparation and fractionating the dose appear beneficial in preclinical studies. While the impact on major congenital malformations in human pregnancies is less clear, ${ }^{8}$ and the effect on neurodevelopment is unknown, in practice, most would advocate such an approach. This is also the case for folate supplementation, where despite the lack of robust evidence of a protective effect against valproate-induced teratogenesis, the prescription of high-dose folate, prescribed before conception and for at least the first 3 months of pregnancy, is presently considered best practice. Minimising the total daily dose has a positive 
Table 1 Major congenital malformation rate for pregnancies exposed to valproate, carbamazepine, lamotrigine and levetiracetam in monotherapy

\begin{tabular}{|c|c|c|c|c|}
\hline \multirow[b]{2}{*}{ Registry } & \multicolumn{4}{|c|}{ Major congenital malformation rate following antiepileptic drug exposure } \\
\hline & Valproate & Carbamazepine & Lamotrigine & Levetiracetam \\
\hline $\begin{array}{l}\text { UK and Ireland Epilepsy and } \\
\text { Pregnancy Registry }\end{array}$ & $\begin{array}{l}82 / 1200 \\
(6.7 \%, \mathrm{Cl} 5.5 \% \text { to } 8.3 \%)\end{array}$ & $\begin{array}{l}43 / 1657 \\
(2.6 \%, \mathrm{Cl} 1.9 \% \text { to } 3.5 \%)\end{array}$ & $\begin{array}{l}49 / 2098 \\
(2.3 \%, \text { Cl } 1.8 \% \text { to } 3.1 \%)\end{array}$ & $\begin{array}{l}2 / 304 \\
(0.7 \%, \mathrm{Cl} 0.2 \% \text { to } 2.5 \%)\end{array}$ \\
\hline $\begin{array}{l}\text { European Registry of Antiepileptic } \\
\text { Drugs and Pregnancy }{ }^{4}\end{array}$ & $\begin{array}{l}\text { Dose <700 mg: } 24 / 431 \\
\text { ( } 5.6 \%, \text { Cl } 3.6 \% \text { to } 8.2 \%) \\
\text { Dose } \geq 700 \text { to }<1500 \mathrm{mg}: 50 / 480 \\
\text { (10.4\%, CI } 7.81 \% \text { to } 13.5 \%) \\
\text { Dose } \geq 1500 \mathrm{mg}: 24 / 99 \\
(24.2 \%, \text { Cl } 16.2 \% \text { to } 33.9 \%)\end{array}$ & $\begin{array}{l}\text { Dose <400 mg: } 5 / 148 \\
(3.4 \%, \text { Cl } 1.1 \% \text { to } 7.7 \%) \\
\text { Dose } \geq 400 \text { to }<1000 \mathrm{mg}: 56 / 1047 \\
\text { (5.3\%, Cl } 4.1 \% \text { to } 6.9 \%) \\
\text { Dose } \geq 1000 \mathrm{mg}: 18 / 207 \\
(8.7 \%, \text { Cl } 5.2 \% \text { to } 13.4 \%)\end{array}$ & $\begin{array}{l}\text { Dose <300 mg: } 17 / 836 \\
(2.0 \%, \mathrm{Cl} 1.2 \% \text { to } 3.2 \%) \\
\text { Dose } \geq 300 \mathrm{mg}: 20 / 444 \\
(4.5 \%, \mathrm{Cl} 2.8 \% \text { to } 6.9 \%)\end{array}$ & NA \\
\hline $\begin{array}{l}\text { North American Antiepileptic Drug } \\
\text { Pregnancy Registry }\end{array}$ & $\begin{array}{l}30 / 323 \\
(9.3 \%, \mathrm{Cl} 6.4 \% \text { to } 13.0 \%)\end{array}$ & $\begin{array}{l}31 / 1033 \\
(3.0 \%, \mathrm{Cl} 2.1 \% \text { to } 4.2 \%)\end{array}$ & $\begin{array}{l}31 / 1562 \\
(2.0 \%, \mathrm{Cl} 1.4 \% \text { to } 2.8 \%)\end{array}$ & $\begin{array}{l}11 / 450 \\
(2.4 \%, \mathrm{Cl} 1.2 \% \text { to } 4.3 \%)\end{array}$ \\
\hline
\end{tabular}

NA, not available.

impact and should be considered in those women where continuation of valproate is felt to be appropriate. Areas requiring further study are whether polytherapy combinations, not containing valproate or combinations containing low-dose valproate in polytherapy, may be safer than medium and high-dose valproate in monotherapy. One study showed that valproate taken as part of polytherapy regimens in total daily doses below $700 \mathrm{mg}$ a day was associated with a major congenital malformation rate of $5.4 \%$, compared with $11.0 \%$ for monotherapy doses of $700-1500 \mathrm{mg}$ a day and $24.0 \%$ for doses above $1500 \mathrm{mg}$ a day. ${ }^{9}$ We do not know if this applies to neurodevelopmental outcomes.

Another challenge is to identify all women with epilepsy who are still taking valproate, but not under the care of specialist epilepsy services. This is especially relevant for those who were prescribed valproate at a young age for generalised epilepsy syndromes, many of whom will be seizure-free and will have been informed that they need to take antiepileptic medication for life. While neurologists may not be best placed to identify these women, being able to offer timely consultations, repeated regularly, will be difficult in already stretched healthcare systems such as the National Health Service (NHS).

So is there evidence that prescribing practices have changed and that the risks of valproate are being communicated? Pregnancy registries have shown falling valproate registrations, ${ }^{10}{ }^{11}$ in favour of the safer-but for some women less effective-alternatives lamotrigine and levetiracetam, ${ }^{3-5} 12$ with lower doses being used. Population-based studies have also reported falling exposures. While not directly comparable, results from the UK General Practice Research Database showed the proportion of women with epilepsy aged 15-44 years taking valproate declined from $40.5 \%$ in 1999 to $29.5 \%$ in $2008 .{ }^{13}$ However, a recent report from NHS England found 18000 of just over 174000 prescriptions for valproate were still being given to women with epilepsy of childbearing years. ${ }^{14}$ Surveys have also shown that more needs to be done to inform women with epilepsy of the risks of valproate, with one, in over 2000 women with epilepsy in the UK, finding that $18 \%$ of women taking valproate did not know the risks posed during pregnancy, and $28 \%$ stating they had not been informed of these. ${ }^{15}$

In conclusion, neurologists are best placed to provide a comprehensive assessment of women with epilepsy who are taking valproate. Any discussions should take account of the wishes of individual woman and be responsive to changing desires over time, and be sensitive to those women who do not desire or cannot have children, and to those for whom valproate is required. Ongoing support of pregnancy registries and similar studies on neurodevelopment should also be encouraged (Figure 1).

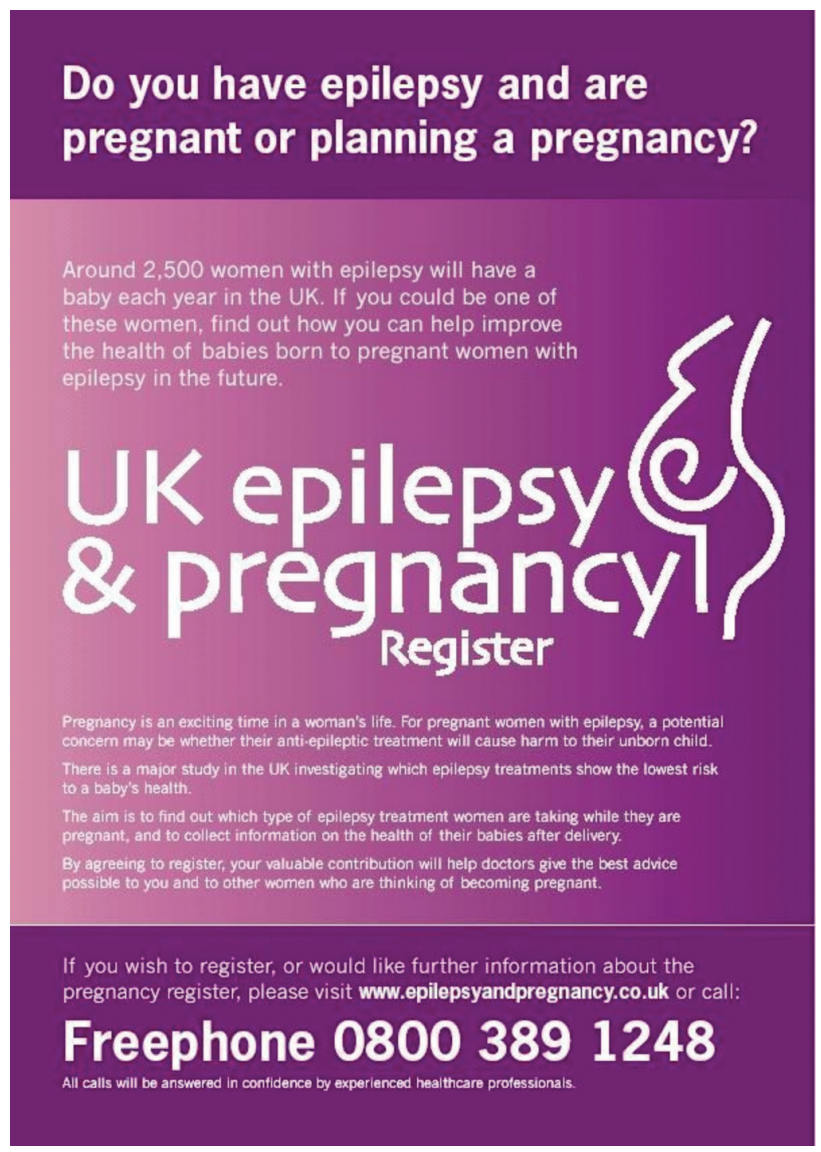

Figure 1 Poster advertising the UK (and Ireland) epilepsy and pregnancy register. 
Contributors JJC had the idea for the paper and wrote it in its entirety.

Funding This research received no specific grant from any funding agency in the public, commercial or not-for-profit sectors.

Competing interests None declared.

Patient consent Not required.

Provenance and peer review Commissioned; externally peer reviewed by Sanjay Sisodiya, London, UK.

Data sharing statement Not relevant.

(C) Article author(s) (or their employer(s) unless otherwise stated in the text of the article) 2018. All rights reserved. No commercial use is permitted unless otherwise expressly granted.

\section{REFERENCES}

1 Centers for Disease Control (CDC). Valproic acid and spina bifida: a preliminary report-France. MMWR Morb Mortal Wkly Rep 1982;31:565-6.

2 DiLiberti JH, Farndon PA, Dennis NR, et al. The fetal valproate syndrome. Am J Med Genet 1984;19:473-81.

3 Campbell E, Kennedy F, Russell A, et al. Malformation risks of antiepileptic drug monotherapies in pregnancy: updated results from the UK and Ireland Epilepsy and Pregnancy Registers. J Neurol Neurosurg Psychiatry 2014;85:1029-34.

4 Tomson T, Battino D, Bonizzoni E, et al. Dose-dependent risk of malformations with antiepileptic drugs: an analysis of data from the EURAP epilepsy and pregnancy registry. Lancet Neurol 2011;10:609-17.

5 Hernández-Díaz S, Smith CR, Shen A, et al. North American AED Pregnancy Registry North American AED Pregnancy Registry. Comparative safety of antiepileptic drugs during pregnancy. Neurology 2012;78:1692-9.

6 Governance of UK. Valproate and risk of abnormal pregnancy outcomes: new communication materials. 2016 https://www. gov.uk/drug-safety-update/valproate-and-of-risk-of-abnormalpregnancy-outcomes-new-communication-materials.

7 Tomson T, Battino D, Bonizzoni E, et al. Withdrawal of valproic acid treatment during pregnancy and seizure outcome: Observations from EURAP. Epilepsia 2016;57:e173-7.

8 Mawhinney E, Campbell J, Craig J, et al. Valproate and the risk for congenital malformations: Is formulation and dosage regime important? Seizure 2012;21:215-8.

9 Tomson T, Battino D, Bonizzoni E, et al. Dose-dependent teratogenicity of valproate in mono- and polytherapy: an observational study. Neurology 2015;85:866-72.

10 Battino D, Bonizzoni E, Craig J, et al. Utilization of antiepileptic drugs during pregnancy: comparative patterns in 38 countries based on data from the EURAP registry. Epilepsia 2009;50:2305-9.

11 Vajda FJ, O'Brien TJ, Graham J, et al. The Australian Register of antiepileptic drugs in pregnancy: changes over time in the epileptic population. J Clin Neurosci 2014;21:1478-82.

12 Weston J, Bromley R, Jackson CF, et al. Monotherapy treatment of epilepsy in pregnancy: congenital malformation outcomes in the child. Cochrane Database Syst Rev 2016;11:CD010224.

13 Nicholas JM, Ridsdale L, Richardson MP, et al. Trends in antiepileptic drug utilisation in UK primary care 1993-2008: cohort study using the General Practice Research Database. Seizure 2012;21:466-70.

14 NHS England. Sodium Valproate Prescribing. 2017. https:// www.england.nhs.uk/publication/prescribing-for-sodiumvalproate

15 Epilepsy Action. Almost one-fifth of women taking sodium valproate for epilepsy still not aware of risks in pregnancy, survey shows. 2018. https://www.epilepsy.org.uk/news/news/ almost-one-fifth-women-taking-sodium-valproate-epilepsy-stillnot-aware-risks-pregnancy 